\title{
The effects of adding "flavour enhancers" on levels of chloropropanediol esters and glycidyl esters in savoury shortbread
}

\author{
Anna Sadowska-Rociek ${ }^{1}$ iD
}

Received: 31 July 2018 / Revised: 4 October 2018 / Accepted: 14 October 2018 / Published online: 24 October 2018

(c) The Author(s) 2018

\begin{abstract}
The effect of the addition of selected flavour enhancers (dried garlic, dried onion, caraway seeds, poppy seeds, kelp, sesame, Herbs de Provence) on levels of chloropropanediol esters (2-MCPDE, 3-MCPDE) and glycidyl esters (GE) was investigated in classic savoury shortbread with standard and reduced salt level. The changes in the amount of esters after a 2-month storage period were also analysed. Finally, selected products with reduced salt level were evaluated by consumers. The obtained results suggested that the MCPDE and GE present in bakery fat were transferred to the dough and partially decomposed during baking. Ester degradation depended on the presence of flavour additives and the amount of salt. The addition of poppy seeds or sesame accelerated the degradation, whereas onion and garlic inhibited the decomposition and, in some cases, promoted the endogenous formation of 3-MCPDE. The added salt also partially inhibited the decomposition of 3-MCPD esters but had no impact on 2-MCPDE changes. After a 2-month storage period, the level of 3-MCPDE increased in all samples that did not contain salt, while in salty products as well as for 2-MCPDE no such trends were observed. GE levels decreased after 2 months in almost all investigated samples. The consumer acceptability tests showed that the addition of poppy seeds or sesame seeds to the shortbread with reduced salt was highly evaluated by consumers. Hence, the addition of these flavour enhancers can mask the reduced salt amount, thereby lowering not only the level of sodium in the diet, but also the levels of toxic contaminants such as MCPDE or GE.
\end{abstract}

Keywords Chloropropanediol esters $\cdot \mathrm{MCPD} \cdot$ Glycidyl esters $\cdot \mathrm{NaCl} \cdot$ Shortbread $\cdot$ Flavour enhancers

\section{Introduction}

Salt, the common name of sodium chloride, due to its function in regulating flavour, taste, colour, and bacteriostatic properties, has been used as a seasoning and preservative in food since ancient times [1, 2]. In the human body, sodium is essential for the maintenance of cellular membrane potential and the absorption of nutrients in the small intestine. Its presence determines the volume of extracellular fluid, thereby maintaining blood pressure [3]. However, excessive consumption of sodium has been associated with negative health effects, including most of all cardiovascular disease and hypertension, stroke, stomach cancer, kidney disease and bone demineralization [3-5]. Therefore, numerous

Anna Sadowska-Rociek

a.sadowska-rociek@ur.krakow.pl

1 Malopolska Centre of Food Monitoring, Faculty of Food Technology, University of Agriculture in Krakow, Balicka Street 122, 30-149 Kraków, Poland national and international organisations have introduced recommendations and actions for lowering sodium chloride levels in foods. Currently, the WHO/FAO provides a guideline of less than $2 \mathrm{~g}$ of sodium intake per day [5].

In most European countries, a major source (nearly $40 \%$ ) of sodium in the diet comes from cereal products such as bread, biscuits, breakfast cereals, pastries, cakes, and cereal snacks [2, 3]. In bakery products, apart from regulating the flavour, salt improves the texture and the water-binding capacity of the dough. Due to its ionic nature it also controls the water activity of product and results in an increased shelf life [6].

The second salt component, chloride, is also an essential element for the human body because it helps in maintaining water balance and is an inherent component of gastric juice regulation [7]. However, chloride ions are considered as precursors of the formation of chloropropanediol esters (MCPDE) [8, 9]. Chloropropanediol esters are the bound forms of 3-monochloropropane-1,2-diol (3-MCPD) or 2-monochloropropane-1,3-diol (2-MCPD) 
with fatty acids. MCPDE and similar compounds, glycidyl esters (GE), are generated from either partial acylglycerols or triacylglycerol at temperatures above $200{ }^{\circ} \mathrm{C}$ in the presence of chloride ions [9]; the level of 3-MCPD esters is correlated with the concentration of $\mathrm{NaCl}$ [8]. Until now, MCPDE and GE were detected mainly in refined edible oils, but recently some authors discovered ester formation during other processes, e.g. baking of biscuits or deep frying $[10,11]$. However, the results provided by other researchers indicate that the endogenous formation of MCPDE and GE is questionable [12, 13].

The European Food Safety Authority (EFSA) Panel on Contaminants in the Food Chain (CONTAM) agreed with the estimate of $100 \%$ release of 3-MCPD from its esters in humans. Latest scientific studies indicate an (almost) entire release of glycidyl from fatty acid esters within the human digestive tract [9]. Free 3-MCPD is classified as a potential carcinogen (Group 2B) [14]. Glycidol was classified by the International Agency for Research on Cancer (IARC) as a probable carcinogenic (group 2A) [15]. The toxicological assessment of 2-MCPD is still insufficient.

Therefore, the reduction of both sodium and chloride ions in bakery items has for some time been one of the goals of the food industry. However, due to the important technological roles of salt in the baking process, it is difficult to reduce $\mathrm{NaCl}$ without affecting the sensory and physicochemical properties of baked products. There are some ways of compensating for the salt reduction, e.g. using the socalled "flavour enhancers", which can help mask changes in the flavour profile as a result of lower salt levels $[1,2]$. The most common "flavour enhancers" are mainly various herbs (thyme, oregano, basil, rosemary, etc.) or spices (onion, garlic, paprika, pepper) [16-20].

On the other hand, in the case of some spices such as garlic or onion, their presence in food that is subjected to heat treatment may lead to an interaction with fat which results in an increase in the level of free 3-MCPD [21]. Increased levels of 3-MCPD esters in deep-fried garlic and onion have also been reported recently [22]. However, no such research has been performed for chloropropanediol esters and glycidyl esters in bakery products with the addition of spices or other flavour additives. There is also a gap in the data concerning changes of esters during storage of bakery products with different salt levels.

Therefore, the main aim of this study was to investigate the effect of the addition of selected flavour enhancers (dried garlic, dried onion, caraway seeds, poppy seeds, kelp, sesame, Herbs de Provence) on levels of chloropropanediol esters (2-MCPDE, 3-MCPDE) and glycidyl esters in classic savoury shortbread (crackers) with standard and reduced levels of salt. Therefore, the impact of adding salt to dough prior heat processing was also examined. Additionally, the changes in the amount of esters during a 2-month storage period were analysed. Finally, selected products with reduced salt level were evaluated by consumers.

\section{Materials and methods}

\section{Chemicals and reagents}

n-Hexane, methanol, tetrahydrofuran, acetone, sulphuric acid (98\%), sodium bromide, sodium hydrogen carbonate, and sodium sulphate were purchased from Chempur S.A., Poland. 3-MCPD, 3-monochloropropane-1,2-diol-d 5 (3-MCPD- $\mathrm{d}_{5}$ ), 3-monobromopropane-1,2-diol (3-MBPD), phenylboronic acid (PBA) were obtained from SigmaAldrich, USA. 2-monochloropropane-1,3-diol (2-MCPD), 2-monochloropropane-1,3-diol-d $\mathrm{d}_{5}$ (2-MCPD- $\left.\mathrm{d}_{5}\right), 3$-monobromopropane-1,2-diol-d $\mathrm{d}_{5}$ (3-MBPD-d $\mathrm{d}_{5}$ ), 1,2-bis-palmitoyl3-chloropropanediol- $\mathrm{d}_{5}$ (PP-3-MCPD- $\mathrm{d}_{5}$ ) 1,3-bis-palmitoyl-2-chloropropanediol- $\mathrm{d}_{5}\left(\mathrm{PP}-2-\mathrm{MCPD}-\mathrm{d}_{5}\right)$ and glycidyl palmitate- $\mathrm{d}_{5}\left(\right.$ PP-Gly- $\left.\mathrm{d}_{5}\right)$ were obtained from LGC Standards (United Kingdom) and Leco Dry (infusorial soil) was from Leco (USA). All reagents were at least of analytical purity.

A sodium sulphate solution of $200 \mathrm{mg} \mathrm{mL}^{-1}(20 \%)$, a saturated solution of sodium hydrogen carbonate, and a solution of sodium hydrogen carbonate $(0.9 \%)$ were prepared in deionised water. Stock $\left(1 \mathrm{mg} \mathrm{mL}^{-1}\right)$, intermediate $\left(100 \mu \mathrm{gL}^{-1}\right)$ and working $\left(2 \mu \mathrm{g} \mathrm{mL}^{-1}\right)$ standard solutions of each chloropropanol as well as 3-MBPD and 3-MBPD- $\mathrm{d}_{5}$ were prepared in ethyl acetate. PP-MCPD- $\mathrm{d}_{5}$, PP-2-MCPD$\mathrm{d}_{5}$, and PP-Gly- $\mathrm{d}_{5}\left(5 \mu \mathrm{g} \mathrm{mL} \mathrm{mL}^{-1}\right)$ were dissolved in ethyl acetate. The PBA solution was prepared by dissolving $5 \mathrm{~g}$ PBA in a $20 \mathrm{~mL}$ mixture of acetone and water $(19: 1, \mathrm{v} / \mathrm{v})$.

\section{Cracker ingredients}

The flavour enhancers used in the study were selected according to their common application in savoury shortbread (crackers): dried onion (Allium cepa L.); caraway seeds (Carum carvi); dried garlic (Allium sativum); poppy seeds (Papaver somniferum L.); sesame seeds (Sesamum indicum L.), and Herbes de Provence mixture. Herbes de Provence mix was prepared in the laboratory according to a traditional recipe that included thyme (Thymus vulgaris), oregano (Origanum vulgare), basil (Ocimum basilicum), rosemary (Rosmarinus officinalis), sage (Salvia officinalis), savory (Satureja hortensis) and marjoram (Origanum majorana) in the proportion of $2: 2: 2: 2: 1: 1: 1(\mathrm{w} / \mathrm{w})$. Additionally, the use of kelp algae (Laminaria japonica) as a flavour additive was also tested due to its high nutritional value [19].

The additives and other ingredients (wheat flour type 500 , bakery fat, salt) were purchased from a local supermarket. The bakery fat contained sunflower and rapeseed oil in varying proportions, palm oil, rapeseed oil partially 
hydrogenated, water, acidified milk, salt $(0.3 \%)$, sugar, emulsifiers (mono- and diglycerides of fatty acids, mono- and diglycerides of fatty acids esterified with citric acid, sunflower lecithin), aroma, annatto, citric acid, vitamins A and D3 (according to the manufacturer). The total fat level in the bakery fat was $80 \%$.

\section{Formulation of crackers}

In the experiment two versions of the savoury shortbread were prepared: (1) with the addition of salt, (2) without salt, in which the final salt amount resulted only from the salt present in the bakery fat. The cracker formulation was based on a standard savoury shortbread recipe that included wheat flour $(1000 \mathrm{~g})$, bakery fat $(500 \mathrm{~g})$, water $(200 \mathrm{~g})$ and salt (optionally, $24 \mathrm{~g}$, in the salty variant). Both versions of the dough were prepared in four replicates, each of which was divided into eight parts. Seven parts were enhanced with the flavour enhancer in the amount of $4 \%$ of the batter (w/w). One part of the batter did not contain any additive (control sample). The dough was cut into $0.5 \mathrm{~cm}$ thick discs of $5 \mathrm{~cm}$ diameter, weighed, and then baked at $200{ }^{\circ} \mathrm{C}$ for $15 \mathrm{~min}$ in a Hendi G5D convection steam oven (Hendi Food Service Equipment, Netherlands). After baking, the crackers were cooled to ambient temperature, weighed once again, and divided into two groups. The first group was analysed immediately after baking, while the second group of biscuits was packed in polyethylene bags, tightly sealed and stored for 2 months. The storage experiment was conducted in an air-conditioned laboratory under storage conditions established according to the Polish standard PN-A-74859:1994 [23], which specifies a temperature of $18 \pm 2{ }^{\circ} \mathrm{C}$ and a relative air humidity of $45 \%$. After the storage, the bags were weighed once again to ensure that no changes in the mass of stored samples occurred.

\section{Determination of 3-MCPDE and GE}

Determination of MCPD esters and glycidyl esters was performed in all samples of crackers, immediately after baking and after a 2-month storage period. All dough ingredients (flour, bakery fat and tested additives) were also analysed for 2-MCPDE, 3-MCPDE, and GE levels. The extraction and determination of fat was performed using $\mathrm{CO}_{2}$ in critical phase using a TFE 2000 (LECO, USA). The amount of the sample from which the fat was extracted varied from 0.3 to $1 \mathrm{~g}$ to obtain the fat amount not more than $100 \mathrm{mg}$. The whole extracted fat was spiked with $270 \mu \mathrm{L}$ of PP2-MCPD- $\mathrm{d}_{5}$, PP-3-MCPD- $\mathrm{d}_{5}$ and PP-Gly- $\mathrm{d}_{5}$. Bromination of GE and acid transesterification was performed according to the procedure described by Zelinkova et al. [24]. The released free forms of diols were then derivatised with $50 \mu \mathrm{L}$ of PBA solution at $90{ }^{\circ} \mathrm{C}$ for $20 \mathrm{~min}$. After cooling,
$500 \mu \mathrm{L}$ of hexane was added, the mixture was shaken vigorously, and $200 \mu \mathrm{L}$ of upper hexane layer was transferred into an insert in an autosampler vial. The extracts were then analysed by GC-MS using Varian IonTrap 4000 GC/MS (Varian, Inc., USA) with a standard DB-5MS column [25]. Limit of quantifications (LOQ) were equal to $4.5 \mu \mathrm{g} \mathrm{kg}^{-1}$ for 3-MCPDE, $11.0 \mu \mathrm{g} \mathrm{kg}^{-1}$ for 2-MCPDE (expressed as free MCPD equivalent) and $9.4 \mu \mathrm{g} \mathrm{kg}^{-1}$ for GE (expressed as glycidol moiety).

\section{Consumer acceptability tests}

A total of 20 consumers (students and employees at the Faculty of Food Technology) were asked to participate in a consumer acceptability test. Crackers were presented as whole pieces on plastic dishes coded with random numbers and served in random order. The products were evaluated on the basis of the acceptability of their appearance, colour, flavour, crispiness, taste, and overall acceptability on a nine-point hedonic scale. The scale of values ranged from "like extremely" to "dislike extremely", corresponding to the highest and lowest scores of "9" and "1", respectively.

\section{Statistical analysis}

All results are presented as the means and standard deviation of four independent replicates. Statistical analyses (one-way analysis of variance with Tukey's post hoc tests) were performed using Statistica software, v. 12.0 (Tulsa, OK, USA). The significance level was established at $p<0.05$.

\section{Results and discussion}

\section{The level of contaminants in dough ingredients}

The esters of 3-MCPD and 2-MCPD were identified in the fat phase of bakery fat at levels of $606 \pm 12 \mu \mathrm{g} \mathrm{kg}^{-1}$ and $190 \pm 6 \mu \mathrm{g} \mathrm{kg}^{-1}$, respectively (expressed as free MCPD, according to EFSA), while the amount of glycidyl esters reached $120 \pm 8 \mu \mathrm{g} \mathrm{kg}^{-1}$ (expressed as glycidol moiety). Other dough ingredients were free of all contaminants.

\section{The level of contaminants in crackers after baking}

Crackers with salt The levels of 3-MCPDE ranged from $114 \mu \mathrm{g} \mathrm{kg}^{-1}$ (products with added poppy seeds) to $187 \mu \mathrm{g} \mathrm{kg}^{-1}$ (crackers with onion) (Fig. 1). Levels of 2-MCPD esters were approximately four times lower (Fig. 2). The lowest amount $\left(14 \mu \mathrm{g} \mathrm{kg}^{-1}\right)$ was found in the crackers with the addition of sesame and the highest was detected in the crackers with kelp $\left(42 \mu \mathrm{g} \mathrm{kg}^{-1}\right)$. Glycidol 


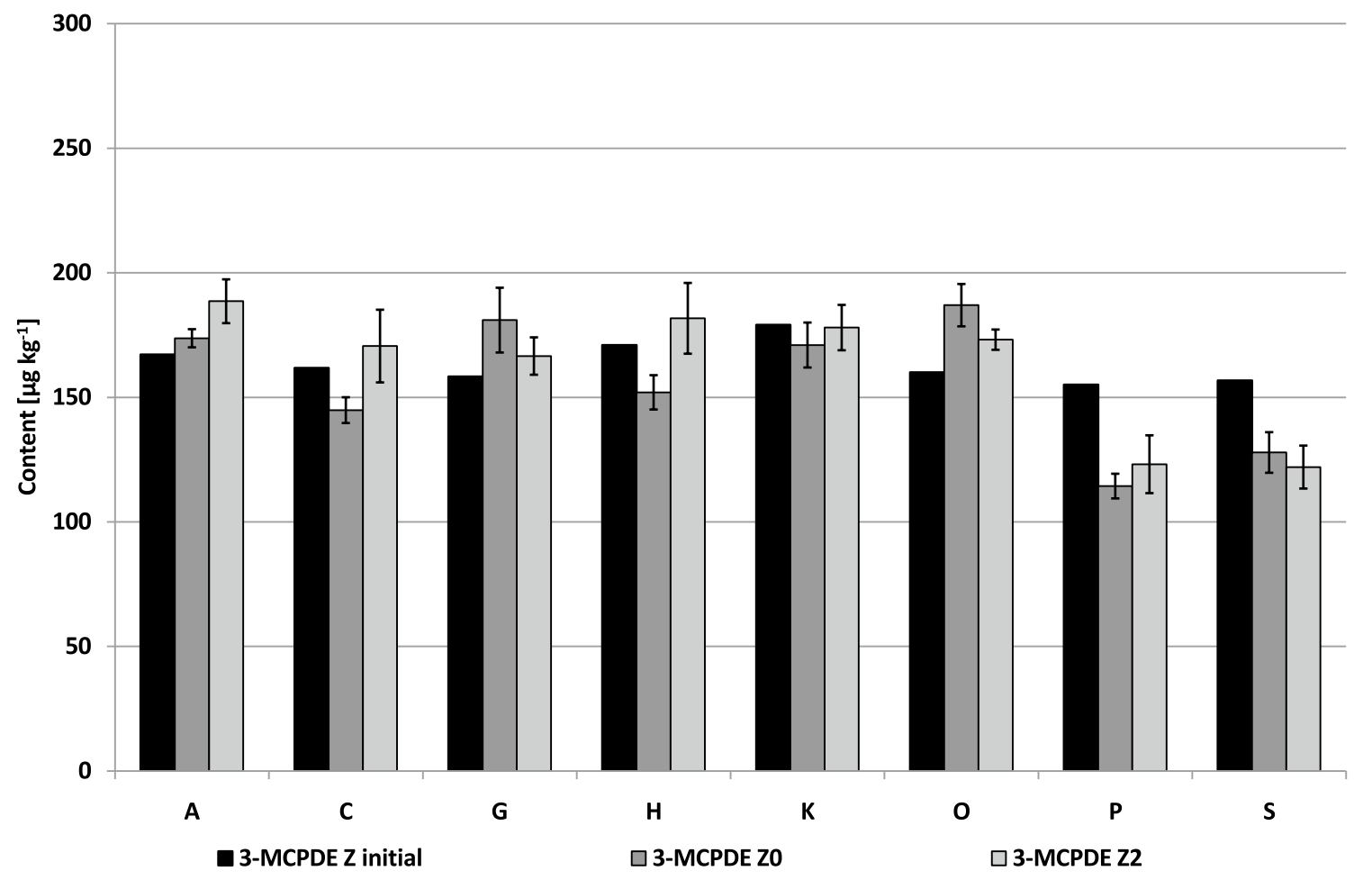

Fig. 1 Content of 3-MCPDE (expressed as free 3-MCPD) in crackers with salt addition; 3-MCPDE $\mathrm{Z}$ initial-levels of 3-MCPDE transferred from bakery fat to crackers (calculated theoretically); 3 -MCPDE Z0-levels of 3-MCPDE in crackers after baking;

ester amount ranged from $12 \mu \mathrm{g} \mathrm{kg}^{-1}$ (poppy seeds) to $27 \mathrm{~g} \mathrm{~kg} \mathrm{k}^{-1}$ (onion) (Fig. 3).

A statistically significant decrease in the 3-MCPDE level, in relation to the control sample, was obtained in the crackers with the addition of Herbs de Provence (11\%), poppy seeds (33\%), sesame (25\%), and caraway seeds (15\%), while the addition of onion resulted in a significant increase (10\%) of the amount of 3-MCPD. Similar effects of poppy seeds were discovered for GE and 2-MCPDE.

Crackers without added salt Similar levels of the investigated contaminants were found (Figs. 4, 5, 6): 3-MCPDE from $118 \mu \mathrm{g} \mathrm{kg}^{-1}$ (poppy seeds) to $206 \mu \mathrm{g} \mathrm{kg}^{-1}$ (onion), 2-MCPDE from $33 \mu \mathrm{g} \mathrm{kg}^{-1}$ (Herbs de Provence) to $58 \mu \mathrm{g} \mathrm{kg}^{-1}$ (garlic) and GE from $10 \mu \mathrm{g} \mathrm{kg}^{-1}$ (poppy seeds) to $34 \mu \mathrm{g} \mathrm{kg}^{-1}$ (onion). The addition of the tested additives influenced the level of 3-MCPDE in the same samples as previously, and the same trends were observed (sesamedecrease of about $10 \%$ in relation to the control sample; poppy seeds-14\%; caraway seeds-13\%); an increase was found once again for the samples containing dried onion $(50 \%)$ and dried garlic $(17 \%)$. The same findings were obtained for 2-MCPDE and GE in the case of added poppy seeds.

Influence of bakery fat contamination According to the data available in the literature, the presence of 2-MCPDE,
3-MCPDE Z2-levels of 3-MCPDE in crackers after a 2-month storage; $A$ kelp, $C$ caraway seeds, $G$ dried garlic, $H$ Herbes de Provence, $K$ control, $O$ dried onion, $P$ poppy seeds, $S$ sesame, error bar is a confidence interval $(95 \%)$

3-MCPDE and GE in baked products can be a result of bakery fat contamination (exogenous origin) or the compounds can be formed during heat treatment (endogenous origin). Based on the initial levels of 2-MCPDE, 3-MCPDE and GE in the bakery fat, it was calculated that baked crackers, depending on the additive used and the salt level, and bearing in mind loss of water, should have contained about $49-58 \mu \mathrm{g} \mathrm{kg}^{-1}$ of 2-MCPDE, $155-185 \mu \mathrm{g} \mathrm{kg}^{-1}$ of 3-MCPDE and $31-58 \mu \mathrm{g} \mathrm{kg}^{-1}$ of GE. Meanwhile, the levels of esters in almost all the studied variants were lower. This suggests that chloropropanediol and glycidyl esters were transferred from the bakery fat to the dough and were further partially decomposed during heat treatment at $200{ }^{\circ} \mathrm{C}$. This phenomenon has already been observed in other studies [10, 26, 27]. However, in this experiment it was discovered that the decomposition depended on the additive added to the dough and the presence of salt. In the control samples with salt, the decrease of 3-MCPDE amount was only about $4 \%$, but in the products without added salt the amount fell to about $26 \%$. The most visible changes in the case of 3-MCPDE in the samples with the flavour enhancers were observed for caraway seeds ( $29 \%$, version without salt) and, in the salty version, for poppy seeds (26\%). For 2-MCPDE, the addition of sesame resulted in a decrease of at least $40 \%$ (non-salty products) and as much as $70 \%$ (salty crackers). 


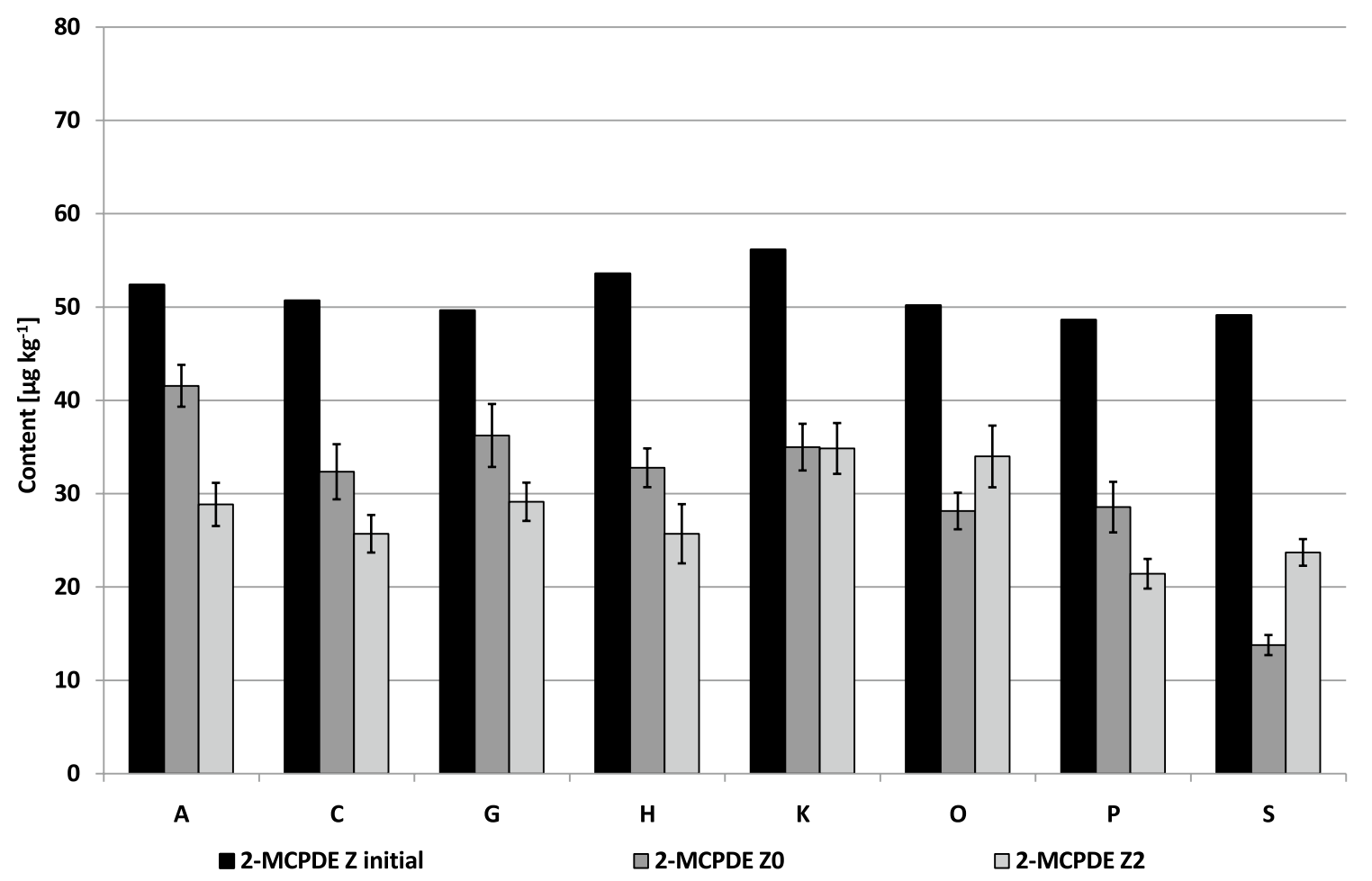

Fig. 2 Content of 2-MCPDE (expressed as free 2-MCPD) in crackers with salt addition; 2-MCPDE $\mathrm{Z}$ initial-levels of 2-MCPDE transferred from bakery fat to crackers (calculated theoretically); 2-MCPDE Z0-levels of 2-MCPDE in crackers after baking;

The most noticeable decrease in GE levels was achieved as the result of the addition of poppy seeds, both for salty and non-salty products. Interestingly, the addition of dried onion or garlic in some cases inhibited the degradation of esters from the bakery fat and even promoted its endogenous formation. This was observed for 3-MCPDE in the products without salt (an increase of about $25 \%$ ), but also for the version to which salt was added (increase $\sim 17 \%$ ). The presence of onion in both types of crackers also resulted in high levels of GE when compared to the initial amount from the bakery fat. The addition of garlic also caused an increase (14\%) of 3 -MCPDE in the salty products and 2-MCPDE (10\%) in the non-salty products. Finally, comparing the average changes of 3-MCPDE levels in all samples between the initial levels from bakery fat and those obtained in the baked products, it was found that 3-MCPD esters were more stable in the products with salt. On the other hand, the addition of salt contributed to a faster decline of 2-MCPDE and GE levels.

Influence of flavour enhancers Considering the observations presented above, it seems that in the case of 3-MCPDE the decomposition was accelerated in the presence of poppy seeds or sesame seeds. This finding is in contrast to the hypothesis of endogenous formation of MCPDE during thermal processing of food because both sesame and poppy seeds contain a high level of fat $\left(53{\mathrm{~g} 100 \mathrm{~g}^{-1} \text { and }}\right.$
2-MCPDE Z2-levels of 2-MCPDE in crackers after a 2-month storage; $A$ kelp, $C$ caraway seeds, $G$ dried garlic, $H$ Herbes de Provence, $K$ control, $O$ dried onion, $P$ poppy seeds, $S$ sesame, error bar is a confidence interval (95\%)

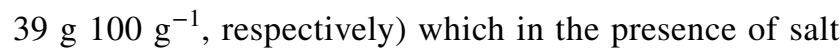
could form more 3-MCPD. No such effect was found during the experiment. On the contrary, the addition of dried onion inhibited 3-MCPDE decomposition and even possibly enhanced its endogenous formation. The significant increase in the level of 3-MCPDE in the samples with the dried onion could be the effect of the presence of allyl alcohol (prop-2en-1-ol), a product of the thermal decomposition of alliin [(S)-allyl-l-cysteine sulphoxide], a cysteine amino acid that is present mostly in garlic, but also in related species such as onion [21]. Recently, Brazil researchers also discovered a high amount of 3-MCPD esters in fried garlic and onion [22].

Influence of salt Comparison of the products with the addition of the same flavour enhancer but with different salt level showed a range of results. The addition of salt resulted in a significant increase (21-36\%, compared to non-salty products) in 3-MCPDE amounts in the control sample and also in the samples with added kelp, Herbes de Provence, and caraway seeds; for the crackers with added poppy seeds or sesame the levels were comparable. For dried onion, the level of 3-MCPDE was slightly lower (about 10\%) in the salty samples than in the samples without salt. Analysis of the amount of 2-MCPD in the products with and without added salt revealed no such trends. The removal of salt from 


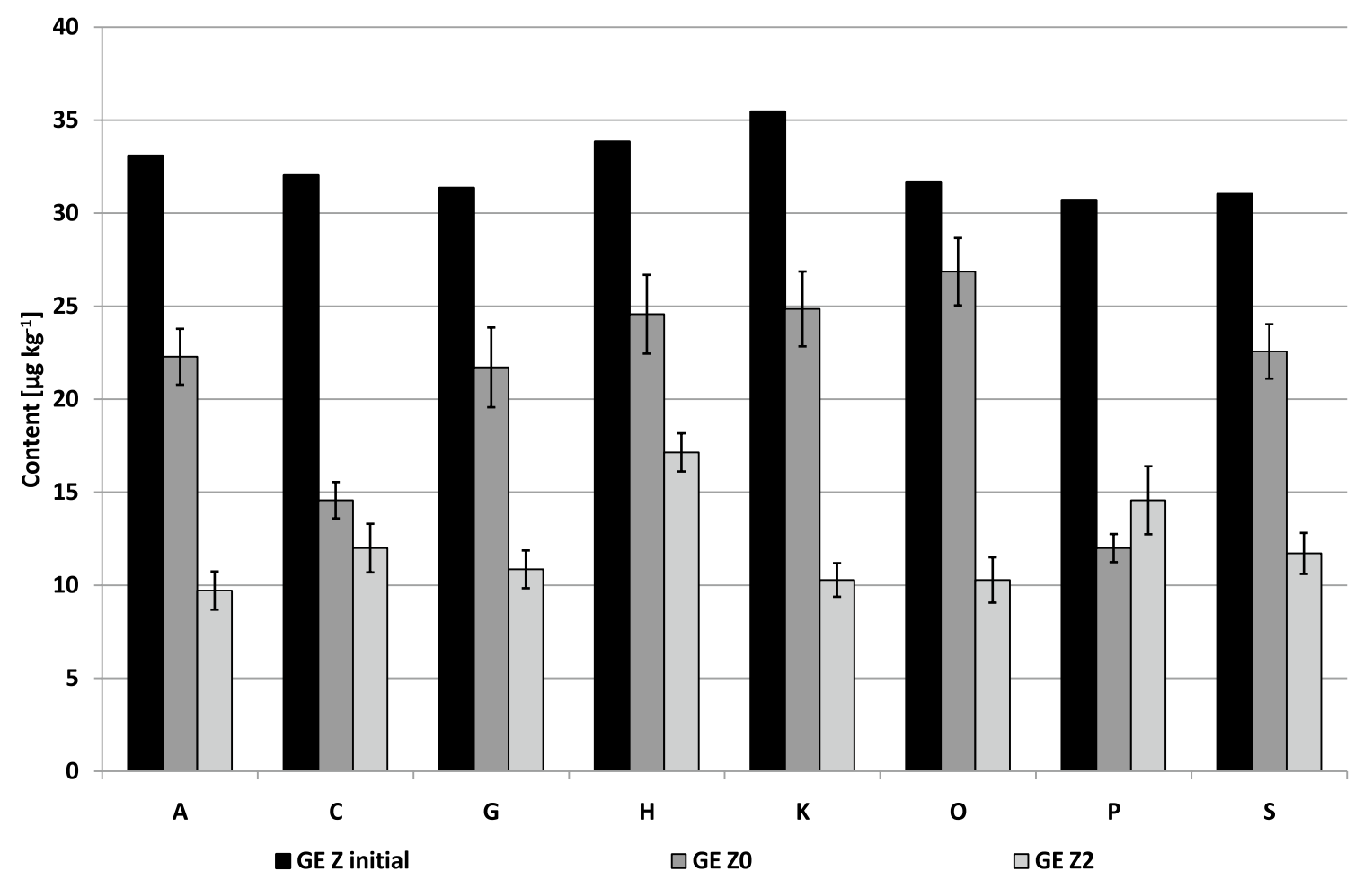

Fig. 3 Content of GE (expressed as glycidol moiety) in crackers with salt addition; GE Z initial-levels of GE transferred from bakery fat to crackers (calculated theoretically); GE Z0-levels of GE in crackers after baking; GE Z2-levels of GE in crackers after a 2-month

the cracker recipe did not cause lower levels of 2-MCPDE; moreover, in almost all cases it contributed to its increase (except for added kelp and Herbes de Provence). For glycidyl esters, the observations were mostly the same: the addition of salt to crackers resulted in a lower GE level in the case of added kelp, onion, sesame, or caraway seeds. No changes were observed for garlic, control samples, and Herbes de Provence. An increase in the GE amount in salty samples was found only for the addition of poppy seeds.

\section{Changes in contaminant content during storage}

After a 2-month storage period, the level of 3-MCPD esters increased in all samples without the addition of salt. In the salty samples, a statistically significant increase was observed for the products with kelp, caraway seeds and Herbes de Provence; a decrease was observed for samples with added onion. For the rest of the samples (garlic, control, poppy seeds, and sesame), the storage did not affect the level of 3-MCPDE. Comparing the changes in the levels of 2-MCPDE after 2-month of storage in the salty samples, most of the additives (kelp, caraway seeds, garlic, Herbs de Provence, poppy seeds) contributed to reducing the amount. An increase was observed only for the samples with onion and sesame. In the crackers without added salt, storage; $A$ kelp, $C$ caraway seeds, $G$ dried garlic, $H$ Herbes de Provence, $K$ control, $O$ dried onion, $P$ poppy seeds, $S$ sesame, error bar is a confidence interval (95\%)

the changes were significant in only five cases: a decrease for the products with garlic, and an increase for kelp, Herbes de Provence, poppy seeds and sesame. Glycidyl esters were more unstable over time and levels decreased significantly in almost all samples, with the exception of the products with poppy seeds (increase of about $90 \%$ in the non salty version) that is unexpected observation. However, it should be mentioned that all the results of the GE amount in the tested samples were still very low and only slightly higher than LOQ.

Comparing the initial levels of esters (from bakery fat) against the amount in the products after baking and after a 2-month storage period, it was found that the esters of 3-MCPD were more stable in the products with added salt than in the version without added salt. Moreover, in nonsalty products, the lowest ester levels were detected in the samples analysed immediately after thermal processing, while long-term storage contributed to an increase in ester levels which became comparable to the initial amount, or even higher. The changes in 2-MCPDE and GE amounts were much more varied; however, it should be emphasised that in almost all cases glycidyl esters decayed during heat treatment and long-term storage. This phenomenon has previously been reported by other authors [28]. 


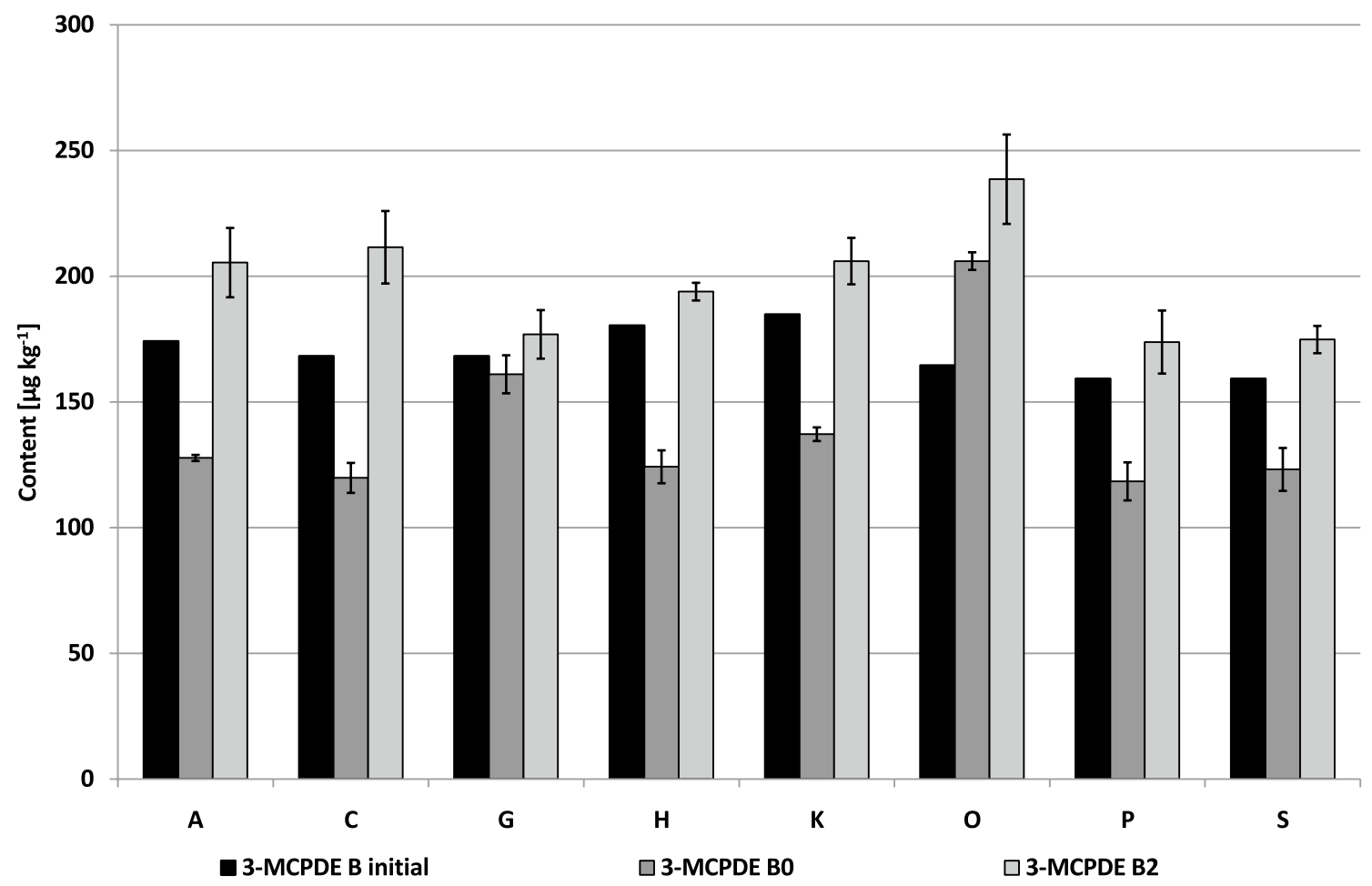

Fig. 4 Content of 3-MCPDE (expressed as free 3-MCPD) in crackers without salt addition; 3-MCPDE B initial-levels of 3-MCPDE transferred from bakery fat to crackers (calculated theoretically); 3-MCPDE B0-levels of 3-MCPDE in crackers after baking;

\section{Consumer acceptability tests}

Considering that one of the aims of the research was to determine if the addition of selected flavour enhancers could mask the reduced level of salt in the examined crackers, selected samples were evaluated in terms of their sensory properties for the consumer. The selection of samples for the consumer acceptability tests was based on the data of the ester levels in the samples without salt. Special attention was paid to the amount of 3-MCPDE because this compound was detected in the highest amount within all analysed esters in all products. Only the samples with 3-MCPDE levels lower than the control sample were further studied; therefore, the samples with the addition of garlic and onion were excluded from the consumer acceptability tests and, finally, five versions of the crackers were evaluated: with the addition of kelp, Herbs de Provence, poppy seeds, caraway seeds and sesame seeds. The results of the tests are summarised in Table 1.

The results showed that the samples with the addition of sesame seeds obtained the best score (6.7). They received
3-MCPDE B2-levels of 3-MCPDE in crackers after a 2-month storage; $A$ kelp, $C$ caraway seeds, $G$ dried garlic, $H$ Herbes de Provence, $K$ control, $O$ dried onion, $P$ poppy seeds, $S$ sesame, error bar is a confidence interval $(95 \%)$

the highest values in the categories of colour, crispness, taste, appearance, all of which enhanced their high overall acceptability. The crackers with poppy seeds were also highly accepted by consumers, with mean scores higher than 6 and the highest scores in the category of flavour. On the contrary, the addition of kelp to the crackers did not gain consumer acceptance, achieving the lowest scores in almost all categories (except appearance) and the lowest mean values (4.89).

\section{Conclusions}

The experiment performed in this study provides new insights into changes in levels of chloropropanediol esters and glycidyl esters in fat-rich bakery items. First, the obtained results indicate that the MCPDE and GE present in bakery fat are transferred to the dough and are then partially decomposed during heat treatment at $200{ }^{\circ} \mathrm{C}$. However, the decomposition is influenced by the presence of 


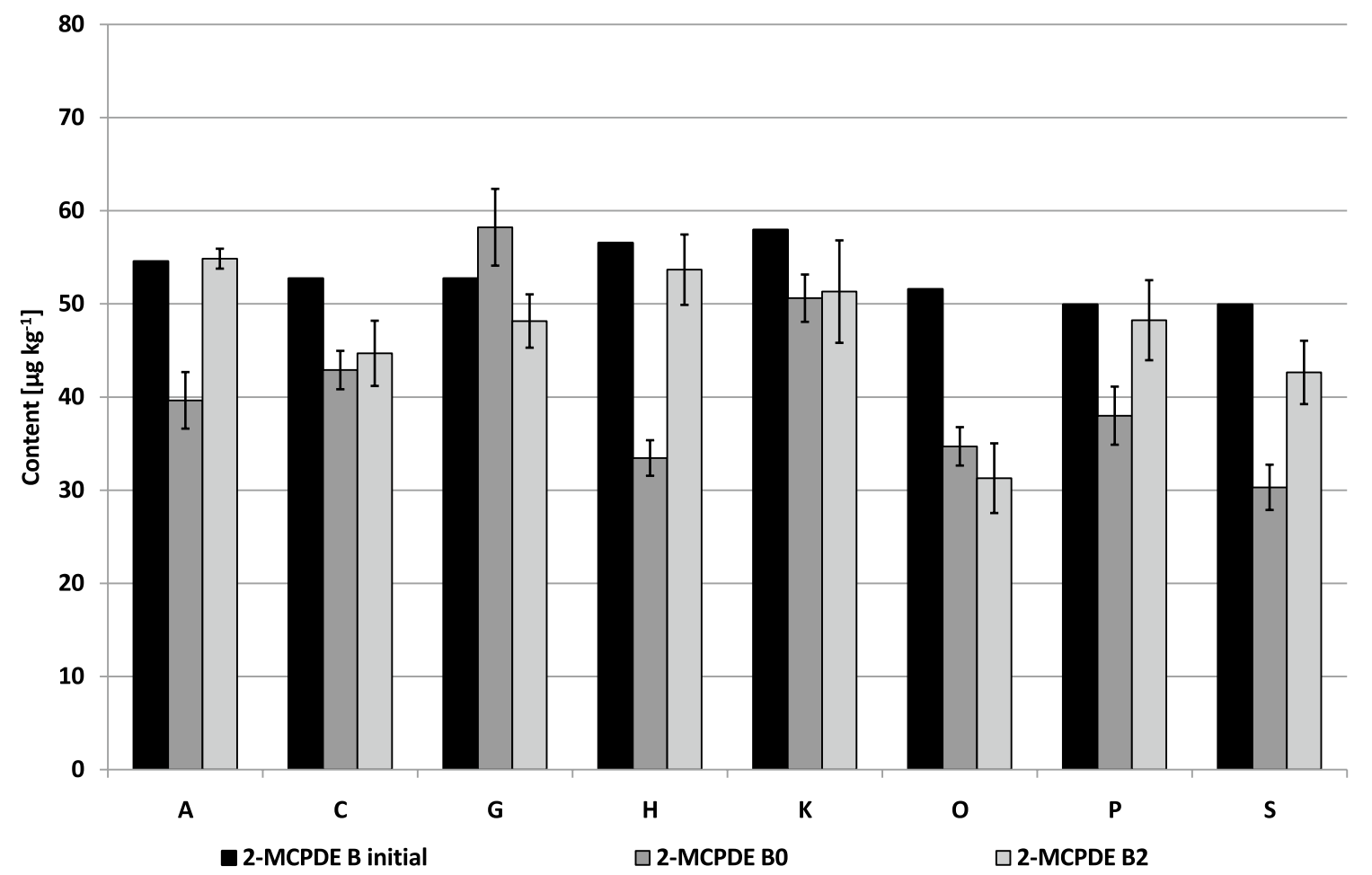

Fig. 5 Content of 2-MCPDE (expressed as free 2-MCPD) in crackers without salt addition; 2-MCPDE B initial-levels of 2-MCPDE transferred from bakery fat to crackers (calculated theoretically); 2-MCPDE B0-levels of 2-MCPDE in crackers after baking;

other dough ingredients such as flavour additives or the amount of salt. The addition of poppy seeds or sesame might contribute to the acceleration of ester degradation, while the compounds present in dried onion and dried garlic can inhibit ester decomposition or even promote the formation of additional amounts of esters during heat treatment. Second, salt added to dough can stabilise the decomposition of 3-MCPD esters but has no influence in the case of 2-MCPDE. Therefore, the presence of salt is not a significant factor that influences levels of MCPDE in the thermal processing of food. Moreover, no additional formation of MCPDE was found in products with higher fat levels, such as crackers with sesame or poppy seeds.
2-MCPDE B2-levels of 2-MCPDE in crackers after a 2-month storage; $A$ kelp, $C$ caraway seeds, $G$ dried garlic, $H$ Herbes de Provence, $K$ control, $O$ dried onion, $P$ poppy seeds, $S$ sesame, error bar is a confidence interval (95\%)

Finally, the consumer acceptability tests demonstrated that the addition of poppy seeds or sesame seeds to crackers in which the level of salt was significantly reduced, were highly evaluated by consumers. In consequence, the addition of these flavour enhancers can mask the reduced salt amount, lowering thereby the level of sodium in the diet, and, at the same time, also reducing the levels of toxic contaminants such as MCPDE or GE. However, it should be remembered that the long-term storage of these products should be avoided because of the risk of increased 3-MCPDE levels. 


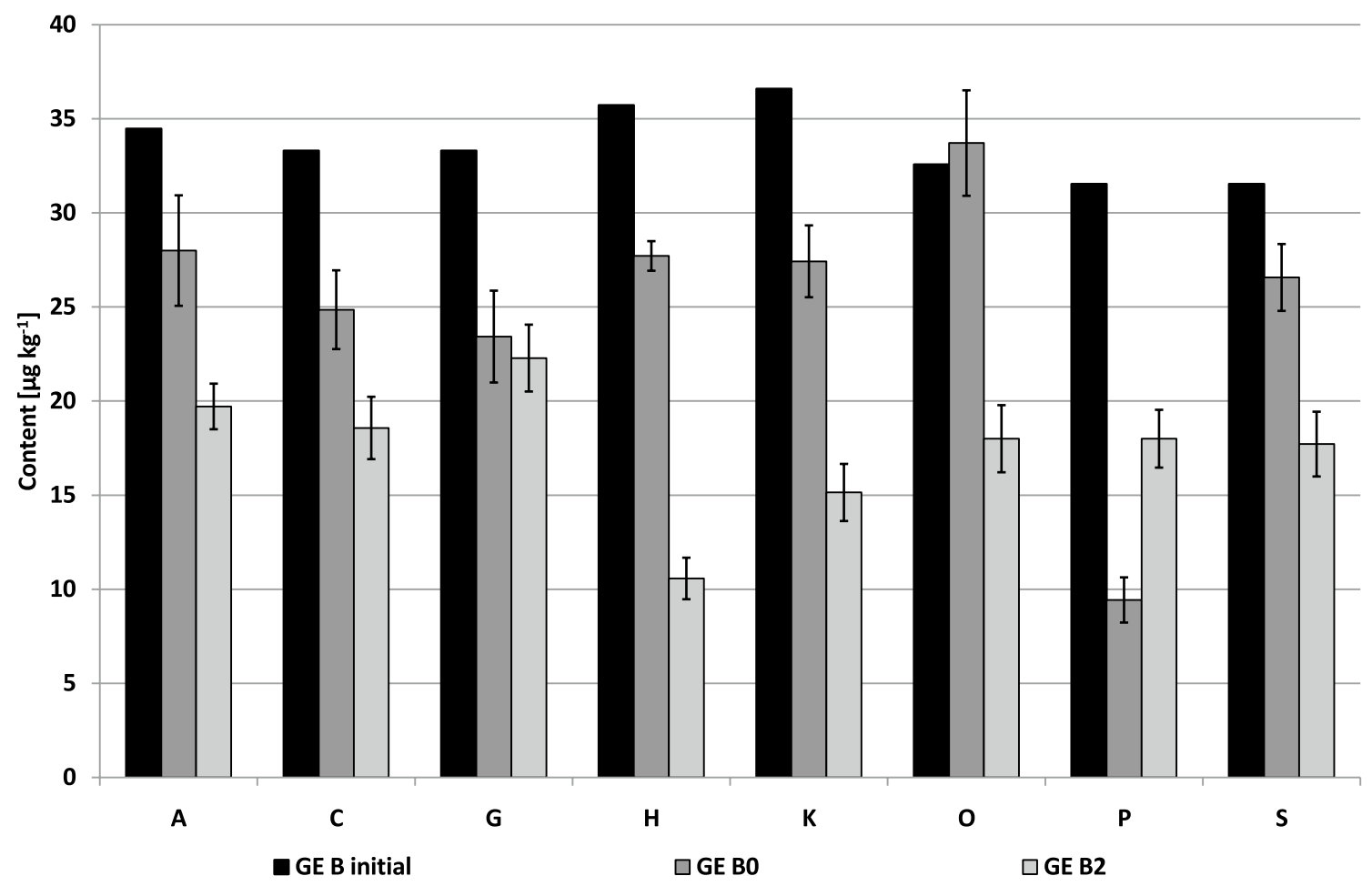

Fig. 6 Content of GE (expressed as glycidol moiety) in crackers without salt addition; GE B initial-levels of GE transferred from bakery fat to crackers (calculated theoretically); GE B0-levels of GE in crackers after baking; GE B2-levels of GE in crackers after a 2-month storage; $A$ kelp, $C$ caraway seeds, $G$ dried garlic, $H$ Herbes de Provence, $K$ control, $O$ dried onion, $P$ poppy seeds, $S$ sesame, error bar is a confidence interval $(95 \%)$
Table 1 Results of the consumer acceptability tests

\begin{tabular}{lrllllll}
\hline & Appearance & Colour & Flavour & Crispness & Taste & Overall acceptability & Mean score \\
\hline A & $5.6^{\mathrm{a}} \pm 1.6$ & $5.3^{\mathrm{a}} \pm 1.5$ & $3.9^{\mathrm{a}} \pm 1.7$ & $6.1^{\mathrm{a}} \pm 2.2$ & $3.6^{\mathrm{a}} \pm 2.0$ & $4.9^{\mathrm{a}} \pm 1.4$ & $\mathbf{4 . 9}$ \\
$\mathrm{C}$ & $6.2^{\mathrm{a}} \pm 1.5$ & $6.4^{\mathrm{b}} \pm 1.3$ & $4.6^{\mathrm{a}} \pm 2.1$ & $6.8^{\mathrm{a}} \pm 2.1$ & $4.6^{\mathrm{a}} \pm 2.5$ & $5.4^{\mathrm{a}} \pm 2.1$ & $\mathbf{5 . 7}$ \\
$\mathrm{H}$ & $5.6^{\mathrm{a}} \pm 2.0$ & $5.3^{\mathrm{a}} \pm 1.9$ & $5.2^{\mathrm{a}} \pm 2.3$ & $6.9^{\mathrm{a}} \pm 1.7$ & $4.7^{\mathrm{a}} \pm 2.3$ & $5.6^{\mathrm{a}} \pm 2.0$ & $\mathbf{5 . 6}$ \\
$\mathrm{P}$ & $6.7^{\mathrm{a}, \mathrm{b}} \pm 1.9$ & $6.7^{\mathrm{b}} \pm 1.7$ & $5.3^{\mathrm{a}} \pm 2.1$ & $7.0^{\mathrm{a}} \pm 1.9$ & $5.9^{\mathrm{b}} \pm 2.5$ & $6.5^{\mathrm{b}} \pm 1.5$ & $\mathbf{6 . 3}$ \\
$\mathrm{S}$ & $7.3^{\mathrm{b}} \pm 1.2$ & $7.2^{\mathrm{b}} \pm 1.7$ & $5.2^{\mathrm{a}} \pm 2.1$ & $7.3^{\mathrm{a}} \pm 1.8$ & $6.5^{\mathrm{b}} \pm 2.7$ & $7.1^{\mathrm{b}} \pm 1.7$ & $\mathbf{6 . 7}$ \\
\hline
\end{tabular}

Mean score (bold value) is calculated as an average from the values obtained in all evaluated categories The same letters in a column indicate no statistically significant differences $(p>0.05)$
Acknowledgements This study was funded by National Science Centre of Poland (Research Project 2017/01/X/NZ9/00212).

\section{Compliance with ethical standards}

Conflict of interest Anna Sadowska-Rociek declares that she has no conflict of interest.

Compliance with ethics requirements This article does not contain any studies with human participants or animals.

Open Access This article is distributed under the terms of the Creative Commons Attribution 4.0 International License (http://creativeco mmons.org/licenses/by/4.0/), which permits unrestricted use, distribution, and reproduction in any medium, provided you give appropriate credit to the original author(s) and the source, provide a link to the Creative Commons license, and indicate if changes were made.

\section{References}

1. Israr T, Rakha A, Sohail M, Rashid S, Shehzad A (2016) Salt reduction in baked products: strategies and constraints. Trends Food Sci Technol 51:98-105

2. Silow C, Axel C, Zannini E, Arendt EK (2016) Current status of salt reduction in bread and bakery products-a review. J Cereal Sci 72:135-145 
3. Kloss L, Dawn Meyer J, Graeve L, Vetter W (2015) Sodium intake and its reduction by food reformulation in the European Union-a review. NFS J 1:9-19

4. Rodrigues FM, Rosenthal A, Tiburski JH, da Cruz AG (2016) Alternatives to reduce sodium in processed foods and the potential of high pressure technology. Food Sci Technol 36:1-8

5. WHO (2012) Guideline: sodium intake for adults and children. World Health Organization (WHO), Geneva

6. IOM (Institute of Medicine) (2010) Strategies to reduce sodium intake in the United States. The National Academies Press, Washington

7. Berend K, van Hulsteijn LH, Gans RO (2012) Chloride: the queen of electrolytes? Eur J Intern Med 23:203-211

8. Svejkovská B, Doležal M, Velíšek J (2006) Formation and decomposition of 3-chloropropane-1,2-diol esters in models simulating processed foods. Czech J Food Sci 24:172-179

9. EFSA (2016) Risks for human health related to the presence of 3- and 2-monochloropropanediol (MCPD), and their fatty acid esters, and glycidyl fatty acid esters in food. EFSA $\mathrm{J}$ 4:4426-4585

10. Mogol BA, Pye C, Anderson W, Crews C, Gökmen V (2014) Formation of monochloropropane-1,2-diol and its esters in biscuits during baking. J Agric Food Chem 62:7297-7301

11. Merkle S, Ostermeyer U, Rohn S, Karl H, Fritsche J (2018) Mitigation strategies for ester bound 2-/3-MCPD and esterified glycidol in pre-fried breaded and frozen fish products. Food Chem 245:196-204

12. Dingel A, Matissek R (2015) Esters of 3-monochloropropane1,2-diol and glycidol: no formation by deep frying during large-scale production of potato crisps. Eur Food Res Technol 241:719-723

13. Dingel A, Matissek R (2017) No endogenous formation of MCPD fatty acid esters and glycidyl fatty acid esters during the baking process of fine bakery wares. Dtsch Lebensmitt Rundsch 113:511-515

14. International Agency for Research on Cancer (IARC) (2012) 3-Monochloro-1,2-propanediol. In: Monographs on the evaluation of carcinogenic risks to humans. Some chemicals present in industrial and consumer products, food and drinking-water, vol 101. IARC Monographs, Lyon, pp 349-374

15. International Agency for Research on Cancer (IARC) (2000) Glycidol. In: Monographs on the evaluation of carcinogenic risks to humans. Some industrial chemicals, vol 77. IARC Monographs, Lyon, pp 469-489

16. Tapsell LC, Hemphill I, Cobiac L, Patch CS, Sullivan DR, Fenech M, Roodenrys S, Keogh JB, Clifton PM, Williams PG, Fazio VA,
Inge KE (2006) Health benefits of herbs and spices: the past, the present, the future. Med J Aust 21:S4-S24

17. Mitchell M, Brutnon NP, Fitzgerald RJ, Wilkinson MG (2013) The use of herbs, spices, and whey proteins as natural flavor enhancers and their effect on the sensory acceptability of reducedsalt chilled ready-meals. J Culin Sci Technol 11:222-240

18. Ghawi SK, Rowland I, Methven L (2014) Enhancing consumer liking of low salt tomato soup over repeated exposure by herb and spice seasonings. Appetite 81:20-29

19. Zhang Y, Cheng Q, Yao Y, Guo X, Wang R, Peng Z (2014) A preliminary study: saltiness and sodium content of aqueous extracts from plants and marine animal shells. Eur Food Res Technol 238:565-571

20. Przygoda B (2010) Possibility of lowering salt content in diet by food selection and use of appropriate cooking methods and spice. Pol J Hum Nutr Metab 37:5-6

21. Stadler RH, Lineback DR (2009) Process-induced food toxicants: occurrence, formation, mitigation, and health risks. Wiley, Hoboken

22. Pavesi Arisseto A, Corrêa Marcolino PF, Vicente E (2015) 3-Monochloropropane-1,2-diol fatty acid esters in commercial deep-fat fried foods. Food Addit Contam A 32(9):1431-1435

23. PN-A-74859:1994 (1994) Preserved pastry goods—packaging, storage and transport

24. Zelinková Z, Giri A, Wenzl H (2017) Assessment of critical steps of a GC/MS based indirect analytical method for the determination of fatty acid esters of monochloropropanediols (MCPDEs) and of glycidol (GEs). Food Control 77:65-75

25. Sadowska-Rociek A, Surma M, Cieślik E (2018) Analysis of acrylamide, 3-monochloropropane-1,2-diol, its esters and glycidyl esters in carbohydrate-rich products available on the Polish market. Rocz Panstw Zakl Hig 69:127-137

26. Hamlet $\mathrm{CG}$ et al (2014) Investigation of the formation of 3-chloropropane-1-2-diol (3-MCPD) from mono- and di-esters of its fatty acids in foods. Raport of the projects FS231006, FS231074, FS231075. Food Standard Agency, London

27. Wong YH, Muhamad H, Abas F, Lai OM, Nyam KL, Tan CP (2017) Effects of temperature and $\mathrm{NaCl}$ on the formation of 3-MCPD esters and glycidyl esters in refined, bleached and deodorized palm oils during deep-fat frying of potato chips. Food Chem 219:126-130

28. Matthäus B, Vosmann K, Weitkamp P, Grundmann D, Kersting HJ (2016) Degradation of glycidyl esters in RBD palm oil as a function of storage conditions. Eur J Lipid Sci Technol 118:418-424 